\title{
The experimental investigations of peculiarities of metalorganic compounds sublimation
}

\author{
Elena Bochkareva ${ }^{1}$, Igor Igumenov ${ }^{2}$, and Vladimir Lukashov ${ }^{1,2 *}$ \\ ${ }^{1}$ Kutateladze Institute of Thermophysics, 630090 Novosibirsk, 1 Lavrent'iev ave., Russia \\ ${ }^{2}$ Nikolaev Institute of Inorganic Chemistry, 630090 Novosibirsk, 3 Lavrent'iev ave., Russia
}

\begin{abstract}
The paper presents the results of experimental investigations of convective heat and mass transfer by sublimation of a single particle of metallorganic compounds mixture in an argon flow. The gas temperature is $180-290^{\circ} \mathrm{C}$, the flow velocity is up to $2 \mathrm{~m} / \mathrm{s}$. The influence of the $\mathrm{Zr}(\mathrm{dpm})_{4}$ and $\mathrm{Y}(\mathrm{dpm})_{3}$ proportions on the characteristics of the transport processes was considered. An increase in the fraction of the more fusible component reduces the temperature of the particle during the sublimation process.
\end{abstract}

\section{Introduction}

At present, chemical vapor deposition of metal complexes with organic ligands (MO CVD Metal-Organic Chemical Vapor Deposition) is one of the most promising methods for the nanostructured materials formation. The coating is formed by the decomposition of an isolated molecule of a volatile metal compound with an organic ligand (precursor) on a heated surface. This makes it possible to realize practically any coating variants starting from a system of unbound nanoparticles up to continuous micron layers by changing the experimental parameters. The low saturated vapor pressure at the operating temperature of the sublimation process and the low thermal stability of the compounds do not allow the concentration of the precursor vapor in the precipitation zone to be sufficient to produce coatings of the required thickness at a high velocity when applying protective coatings using metal beta-diketonates. Currently, one of the problems is to increase the sublimation intensity of the precursor particles in the carrier gas flow, which needs to be solve in order to develop the MO CVD technology. The thermodynamic aspects of the processes of sublimation of precursors and their relationship to the structural characteristics of the compound have been studied quite widely [1,2] but the kinetics of vaporization (sublimation rate) of this class of compounds has not been studied. There are a limited number of studies related to heat and mass transfer under such conditions [3, 4] and less studied transport processes during the sublimation of binary mixtures. The results of such experiments are extremely necessary when developing a 'single-source delivery system' for MO CVD reactors.

The paper presents the results of experimental studies of the kinetics of sublimation of a single spherical particle of $\mathrm{Zr}(\mathrm{dpm})_{4} / \mathrm{Y}(\mathrm{dpm})_{3}$ mixtures in an argon flow. The choice as a research object such combination of precursors is determined by the breadth of their

*Corresponding author: luka@itp.nsc.ru 
application in MO CVD deposition processes of high-temperature ceramic coatings stabilized with yttrium oxide (YSZ). A feature of this system is the significantly different melting points of the investigated compounds $-179{ }^{\circ} \mathrm{C}$ and above $310{ }^{\circ} \mathrm{C}$ for $\mathrm{Y}(\mathrm{dpm})_{3}$ and $\mathrm{Zr}(\mathrm{dpm})_{4}$, respectively.

\section{Experimental procedure}

Samples of $\operatorname{Zr}(\mathrm{dpm})_{4}$ and mixtures of $\mathrm{Zr}(\mathrm{dpm})_{4} / \mathrm{Y}(\mathrm{dpm})_{3}$ (zirconium tetrakisdipivaloylmethanate and yttrium tris-dipivaloylmethane respectively) were prepared for the study of heat and mass transfer during sublimation. The samples were spheres with a diameter $\mathrm{d}_{0}=4 \mathrm{~mm}$ formed from small $(20-50 \mu \mathrm{m})$ crystals with the thermocouple jammed into the center of the sphere. To measure the temperature the K-type thermocouples with a wire diameter of $100 \mu \mathrm{m}$ were used. The raw material was wetted with heptane and pressed to obtain a spherical bead using metallic mold. The mixture "1:1" consisting of equal mass fractions of $\mathrm{Zr}(\mathrm{dpm})_{4}$ and $\mathrm{Y}(\mathrm{dpm})_{3}$ additionally reinforced with glass fiber.

A sample with an initial normal temperature was set in a flow of argon at a constant temperature. The gas flow preparation system was placed inside a thermo stated housing (see Figure 1), equipped with PID control systems. The temperature was set in the range $\mathrm{t}_{0}=210 \ldots 290{ }^{\circ} \mathrm{C}$. The gas flow was a free jet flowing out of a profiled nozzle $12 \mathrm{~mm}$ in diameter. Special measurements were carried out using a gradient radiant flow sensor which showed that the contribution of the radiant flux to the total heat flux on the jet axis at a distance of $12 \mathrm{~mm}$ from the nozzle cut did not exceed $20 \%$. The test sample was placed at this point. Thus, the experimental setup made it possible to investigate convective heat and mass transfer during the sublimation of a single spherical particle.

The gas supply in our experiments was carried out by the digital flow controllers and was set to be equal constant value 8 standard liters per minute. When the studied particle introduced into the flow, its size was record with a Digi Scope II v3 digital microscope. The method for determining the particle size was to find the effective diameter of the sample. The effective diameter was determined from the volume of the ellipse because the particle shape is more similar to elliptical in the sublimation process.

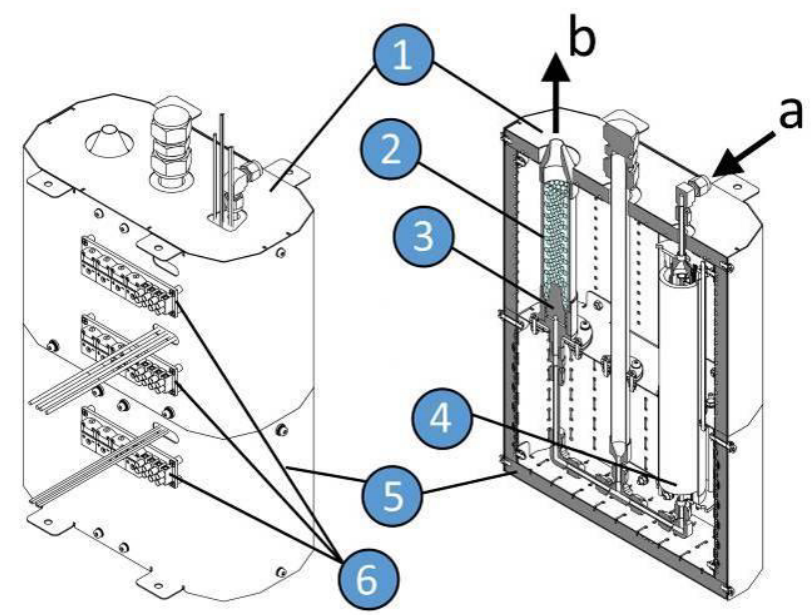

Fig. 1. The scheme of the device for the flow preparation: a - supply of inert gas, $b$ - outlet of heated gas; 1 - upper part of the thermo-stat, 2 - nozzle apparatus filled with quartz beads, 3 - gas distributor, 4 - tubular heater, 5 - lower part of the thermostat, 6 - electrical commutation unit. 


\section{Results}

Photos of the samples are show in Figure 2. The exposure time was $1200 \mathrm{~s}$ for the 1:1 mixture and $2400 \mathrm{~s}$ for other mixtures, and the argon temperature was $240{ }^{\circ} \mathrm{C}$. The results of the experiments showed that during the first $\tau \sim 100$ seconds after the material was set in the argon flow, the sample was heat to a certain temperature ts which in the future remained practically constant. At the argon temperature $\mathrm{t}_{0}=210 \ldots 240{ }^{\circ} \mathrm{C}$ the $" 1: 1 "$ mixture changed to a liquid state. In this case the glass fiber reinforcement was necessary to avoid the drop falling off from the thermocouple. The visualization showed that the mixtures with a large content of $\operatorname{Zr}(\mathrm{dpm})_{4}-" 3: 1 "$ or "10:1" remained in a solid state in the entire investigated range of argon temperatures.

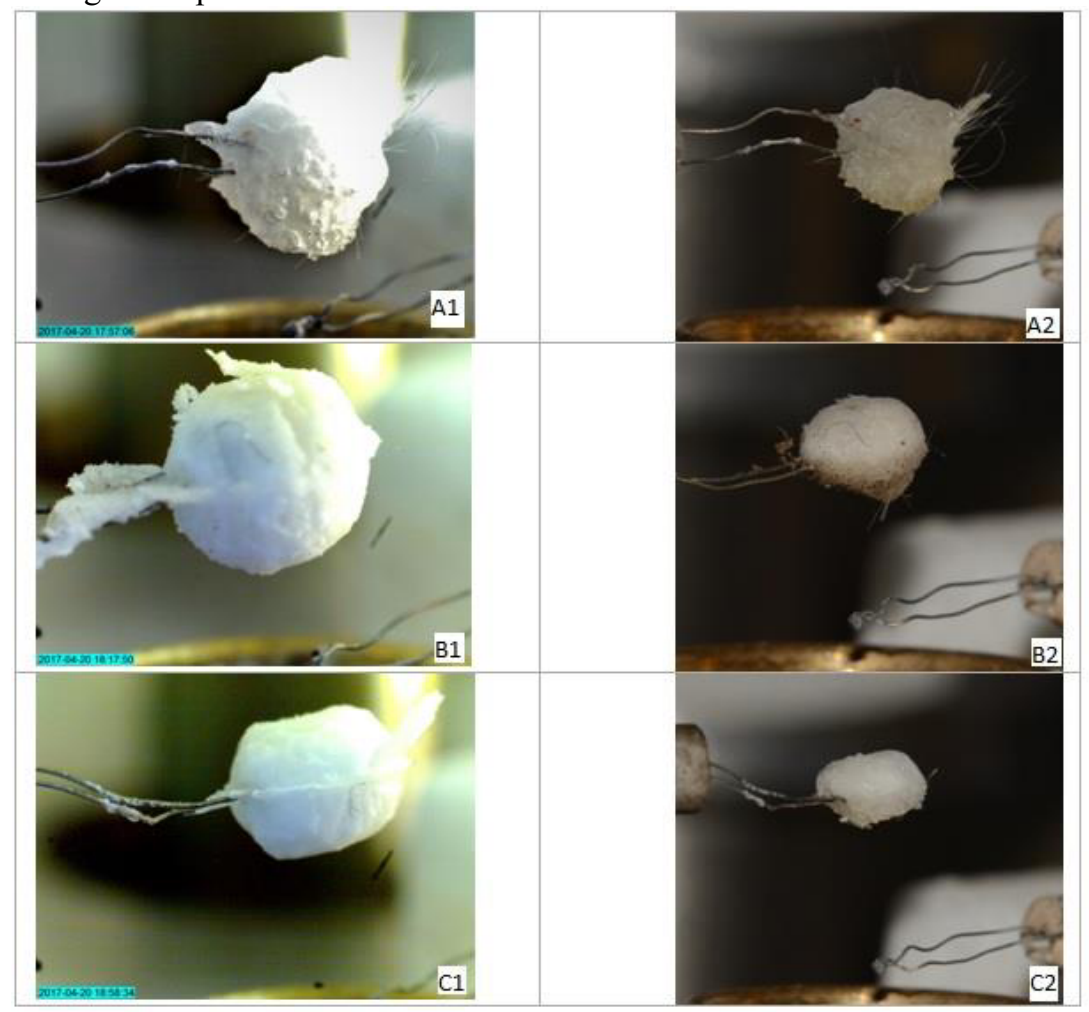

Fig. 2. Particles of different $\mathrm{Zr}(\mathrm{dpm})_{4} / \mathrm{Y}(\mathrm{dpm})_{3}$ mixture during sublimation in an argon flow. $\mathrm{A} 1, \mathrm{~A} 2$ $-\ll 1: 1 » ; \mathrm{B} 1, \mathrm{~B} 2-\ll 3: 1 » ; \mathrm{C} 1, \mathrm{C} 2-\ll 10: 1 »$.

The readings of the thermocouple built into the sample are show in Figure 3. The melting of the sample occurred during the warm-up, after the establishment of a stationary regime any features related to the preferential sublimation of the more fusible $Y(\mathrm{dpm})_{3}$ were not observed.

The intensity of mass transfer can be estimate using the time dependence of the relative particle diameter. In the temperature interval $t_{0}=210-240{ }^{\circ} \mathrm{C}$ the increase of the $\mathrm{Y}(\mathrm{dpm})_{3}$ fraction increases the intensity of the process. When the temperature of the gas flow rises to $290{ }^{0} \mathrm{C}$, the kinetics of the processes changes (Figure 4). When the sublimation of $\mathrm{Zr}(\mathrm{dpm})_{4} / \mathrm{Y}(\mathrm{dpm})_{3}$ mixture takes place the rate of change of the relative diameter becomes markedly less than with the sublimation of pure $\operatorname{Zr}(\mathrm{dpm})_{4}$ substance. 


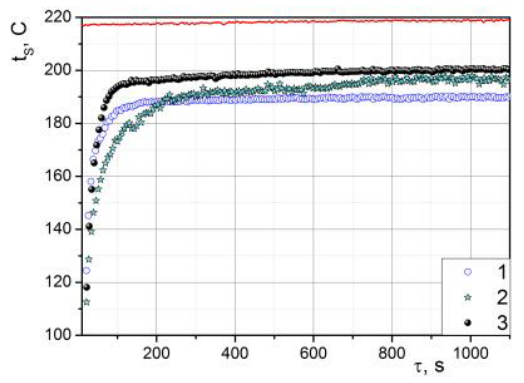

Fig. 3. The temperature of binary mixture sample during sublimation in Ar flow with $\mathrm{t}_{0}=219^{\circ} \mathrm{C}$. 1$\ll 1: 1 » ; 1-\ll 3: 1 » ; 1-\ll 10: 1 »$ mixture.

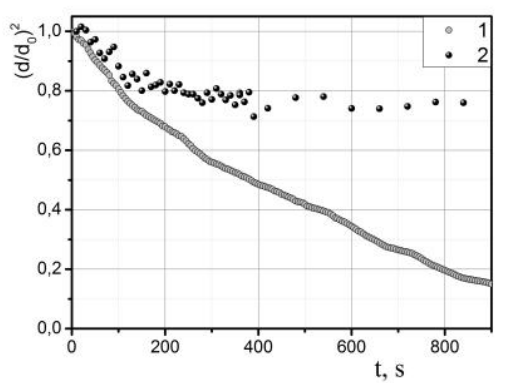

Fig. 4. Dynamics of the diameter of a precursor particle upon sublimation into an argon flow $\mathrm{Ar}$, $\mathrm{t}_{0}=290-291^{\circ} \mathrm{C}, \mathrm{U}_{0}=1.2 \mathrm{~m} / \mathrm{s} .1-\mathrm{Zr}(\mathrm{dpm})_{4} ; 2-$ $\mathrm{Zr}(\mathrm{dpm})_{4} / \mathrm{Y}(\mathrm{dpm})_{3} \ll 10: 1 »$ mixture.

Perhaps this may be due to the transition from phase transition from surface of sphere to the sublimation inside the surface of the pores. In the last case the time dependence of the relative particle diameter ceases to characterize the sample mass transfer.

\section{Conclusion}

Experimental data on the heat and mass transfer processes during the sublimation of $\mathrm{Zr}(\mathrm{dpm})_{4} / \mathrm{Y}(\mathrm{dpm})_{3}$ mixtures for various compositions are obtained. At argon temperature up to $240{ }^{\circ} \mathrm{C}$, the addition of a more fusible $\mathrm{Y}(\mathrm{dpm})_{3}$ lowers the temperature of the sample and increases the rate of change in the relative diameter of the particle. As the temperature of the gas flow rises to $290{ }^{\circ} \mathrm{C}$, the kinetics of the processes change, this may be related to the sublimation process inside the pores.

This work was supported by the Russian Science Foundation (grant No. 16-19-10325).

\section{References}

1. A.M. Igoshkin, I.F. Golovnev, V.V. Krisyuk, I.K. Igumenov, J. Struct. Chem. 57, 6 (2016)

2. V.V. Krisyuk, I.A. Baidina, A.E. Turgambaeva, Kyzy S. Urkasym, I.V. Korolkov, T.P. Koretskaya, I.K. Igumenov, J. Organom. Chem. 819 (2016)

3. A.N. Cherepanov, V.P. Shapeev, L.G. Semin, V.K. Cherepanova, I.K. Igumenov, A.N. Mikheev, N.V. Gelfond, N.B. Morozova, J. Adv. Manufacturing Techn. 44, 4 (2003)

4. N.V. Gelfond, A.N. Mikheev, N.B. Morozova, N.E. Gelfond, I.K. Igumenov, Int. J. Therm. Sci. 42, 8 (2003) 